\title{
PENINGKATAN PENGETAHUAN DAN KETERAMPILAN PENGUKURAN TEKANAN DARAH PADA PASIEN HIPERTENSI BAGI KADER KESEHATAN DI PUSKESMAS SAWANGAN DEPOK
}

\section{IMPROVEMENT OF KNOWLEDGE AND SKILL MEASUREMENT OF BLOOD PRESSURE IN HYPERTENSION PATIENTS FOR CADRES' HEALTH CARE AT HEALTH CENTER SAWANGAN DEPOK}

\author{
Citra Ayu Aprilia ${ }^{1)}$, Mila Citrawati ${ }^{2)}$, Yanti Harjono Hadiwiardjo ${ }^{3)}$ \\ ${ }^{1,2,3}$ Program Studi Sarjana Kedokteran, Fakultas Kedokteran, Universitas Pembangunan \\ Nasional Veteran Jakarta \\ ${ }^{1}$ Email: citra.ayuaprilia@upnvj.ac.id
}

\begin{abstract}
Abstrak: Rata-rata prevalensi penderita hipertensi di seluruh Indonesia adalah 31,7\%. Diperkirakan bahwa pada tahun 2025 persentase orang dengan hipertensi akan meningkat $24 \%$ di negara maju dan $80 \%$ di negara berkembang. Pencegahan dan pemantauan hipertensi dapat dilakukan melalui program Puskesmas atau Posyandu. Karakteristik responden untuk melakukan pengabdian masyarakat adalah kader yang mengawasi masyarakat yang memiliki penyakit terbanyak yaitu hipertensi. Pengabdian ini dilakukan dengan kuliah aktif dan diskusi dengan responden. Dari kegiatan ini diketahui bahwa kader sudah mengetahui hipertensi dan cara pencegahan dari komplikasi dan pengukuran tekanan darah mandiri dan periodik oleh kader. Jadi, di masa depan harus ada upaya promosi kesehatan kreatif dan menargetkan orang / kelompok yang tepat sehingga dapat membawa perubahan ke arah yang lebih baik.
\end{abstract}

Kata Kunci: hipertensi, kader, keterampilan, pengetahuan, tekanan darah

\begin{abstract}
The average prevalence of hypertension sufferers throughout Indonesia is $31.7 \%$. It is estimated that in 2025 the percentage of people with hypertension will increase by $24 \%$ in developed countries and $80 \%$ in developing countries. Prevention and monitoring of hypertension can be done through the Puskesmas or Posyandu program. Characteristics of respondents to conduct community service are kader as participants who oversee the community who have the most illnesses are hypertension. This dedication is carried out with active lectures and discussions with participants. From these activities it is known that people already know the hypertension and the way of prevention from the complication and independent and periodic blood pressure measurement by cadre. So, in the future there should be a creative health promotion effort and target the right people / groups that can bring about change.
\end{abstract}

Keywords: Blood pressure, hypertension, cadre, knowledge, skill.

\section{PENDAHULUAN}

Indonesia merupakan contoh negara berkembang dengan prevalensi penderita hipertensi yang tinggi. Rata-rata prevalensi penderita hipertensi di seluruh Indonesia sebesar 31,7\%. Diperkirakan di tahun 2025 persentase 
INTEGRITAS : Jurnal Pengabdian

Vol 4, No 2, Desember 2020

ISSN 2580 - 7978 (cetak) ISSN 2615 - 0794 (online)

penderita hipertensi meningkat sebesar $24 \%$ pada negara maju dan $80 \%$ pada negara berkembang (Yuli Ernawati, 2016).

Hipertensi adalah suatu penyakit yang disebabkan adanya gangguan pembuluh darah yang pada umumnya pasien tidak mengetahui sebelumnya apabila tidak dilakukan pengukuran tekanan darah. Pasien hipertensi juga tidak merasakan tanda gejala sebelum mengalami komplikasi yang lebih lanjut (Kemenkes, 2019).

Hampir semua konsensus/pedoman utama baik dari dalam walaupun luar negeri, menyatakan bahwa seseorang akan dikatakan hipertensi bila memiliki tekanan darah (TD) sistolik $\geq 140 \mathrm{mmHg}$ dan atau TD diastolik $\geq 90 \mathrm{mmHg}$, pada pemeriksaan yang berulang. Tekanan darah sistolik merupakan pengukuran utama yang menjadi dasar penentuan diagnosis hipertensi (Arieska Ann Soenarta, dkk, 2015).

Pusat Kesehatan Masyarakat yang selanjutnya disebut Puskesmas adalah fasilitas pelayanan kesehatan yang menyelenggarakan upaya kesehatan masyarakat dan upaya kesehatan perseorangan tingkat pertama, dengan lebih mengutamakan upaya promotif dan preventif, untuk mencapai derajat kesehatan masyarakat yang setinggi-tingginya di wilayah kerjanya (Kemenkes, 2014). Puskesmas Sawangan Depok adalah salah satu puskesmas kecamatan Depok yang terletak dengan alamat J1. Raya Muchtar No.73, Sawangan Baru, Kec. Sawangan, Kota Depok, Jawa Barat 16511. Pencegahan dan pemantauan hipertensi dapat dilakukan melalui program Puskesmas atau Posyandu yang merupakan kepanjangan tangan dari puskesmas (Wahyuni Endah dkk, 2019). Karakteristik responden untuk melakukan PKM adalah kader yang mengawasi warga yang mengalami penyakit terbanyak berupa hipertensi.

\section{Permasalahan Mitra}

Menurut Profil Kesehatan Kota Depok Tahun 2017 menyatakan untuk golongan umur 15-44 tahun penyakit Infeksi Saluran Pernafasan Atas (ISPA) menduduki posisi pertama sebesar $14,21 \%$, kemudian di posisi kedua adalah 
INTEGRITAS : Jurnal Pengabdian

Vol 4, No 2, Desember 2020

ISSN $2580-7978$ (cetak) ISSN 2615 - 0794 (online)

penyakit Hipertensi sebesar 13,22\%. Laporan LBI Puskemas dan laporan Rumah Sakit tahun 2017 menyatakan diagnosa penyakit hipertensi esensial mendominasi pola penyakit sepuluh (10) besar terbanyak, yakni sebesar 142.023 kasus hipertensi (Dinas Kesehatan Kota Depok, 2018).

Tingginya persentase warga yang mengalami hipertensi, namun rendahnya angka pasien hipertensi yang kontrol teratur ke puskesmas, hal ini bisa menunjukkan rendahnya pengetahuan mengenai hipertensi dan kesehatan lainnya (Rizki Aulia, 2018). Kepatuhan minum obat pada pasien hipertensi sangatlah penting karena tekanan darah dapat dikontrol dengan minum obat antihipertensi yang teratur, sehingga dalam jangka panjang risiko kerusakan organ-organ penting tubuh seperti otak, jantung dan ginjal dapat dikurangi (BPOM, 2006).

\section{Tujuan PKM}

Pada program Ipteks bagi Masyarakat (IbM) ini, tim pengabdian masyarakat dari Fakultas Kedokteran Universitas Pembangunan Nasional "Veteran” Jakarta yang akan memberikan solusi dari permasalahan.

Tujuan Pengabdian Kepada Masyarakat (PKM) ini diharapkan pada kader kesehatan adanya peningkatan pengetahuan kesehatan tekanan darah tinggi, pengukuran tekanan darah, serta komplikasi pada tekanan darah tinggi (stroke dan Penyakit Jantung Koroner (PJK)) sehingga solusinya bahwa kader kesehatan di wilayah kerja Puskesmas Sawangan Depok dapat melakukan penyuluhan kesehatan hipertensi dan komplikasi serta memahami pengukuran tekanan darah mandiri mandiri dan berkala.

\section{METODE}

Berdasarkan analisis masalah di atas, maka pelaksanaan kegiatan pengabdian dilakukan sebagai berikut. Kegiatan pengabdian masyarakat ini dimulai dengan proses koordinasi kader-kader dari wilayah kerja Puskesmas Sawangan Depok hingga kegiatan PKM berlangsung.

Metode penyelesaian pelaksanaan Pengabdian kepada Masyarakat (PKM) adalah melalui penyuluhan dan penilaian pengetahuan pada kader kesehatan 
INTEGRITAS : Jurnal Pengabdian

Vol 4, No 2, Desember 2020

ISSN 2580 - 7978 (cetak) ISSN 2615 - 0794 (online)

sebanyak 25 orang di wilayah kerja Puskesmas Sawangan Depok mengenai hipertensi dan komplikasinya yaitu stroke dan Penyakit Jantung Koroner (PJK)) serta pelatihan pengukuran tekanan darah dengan sphygmomanometer dan stetoskop yang benar.

Lokasi PKM kami di kelurahan Sawangan Baru yang berada dalam wilayah kerja Puskesmas Sawangan Depok. Evaluasi kegiatan PKM ini adalah mengetahui pengetahuan dan pemahaman kader kesehatan terhadap materi penyuluhan mengenai hipertensi dan komplikasinya dengan memberikan pre dan post test tentang materi penyuluhan.

Pemutaran video senam anti hipertensi. Metode pemutaran video dilakukan dalam mengajarkan senam anti hipertensi pada kader kesehatan di wilayah kerja Puskesmas Sawangan Depok. Senam anti hipertensi perlu diberikan agar kader dapat menguasai gerakan-gerakan dari senam anti hipertensi dan mempraktekannya secara mandiri saat kegiatan senam bersama dengan warga.

\section{HASIL DAN PEMBAHASAN}

Karakteristik sosiodemografi responden. Pelatihan diikuti oleh 25 peserta terdiri dari 25 kader puskesmas wilayah kerja Puskesmas Sawangan Depok. Responden belum pernah mengikuti pelatihan penyuluhan tekanan darah dan komplikasinya serta cara pengukuran tekanan darah secara mandiri. Usia kader kesehatan didominasi berusia 41-50 tahun, diikuti oleh 51-60 tahun, 31-40 tahun, 61-70 tahun, dan 21-30 tahun. Jenis kelamin seluruhnya adalah wanita. Perkejaan pada kader kesehatan di wilayah kerja Puskesmas Sawangan Depok adalah tidak bekerja (Ibu Rumah Tangga). Untuk pendidikan terakhir didominasi di tingkat SMA dan diikuti oleh tingkat SMP.

Hasil evaluasi PKM secara keseluruhan kader kesehatan dapat memahami materi penyuluhan dan pengukuran tekanan darah mandiri serta mengaplikasi kegiatan senam hipertensi dari analisis data kuesioner dengan nilai pre-test 69,55 dan nilai post-test 82,22. 
INTEGRITAS : Jurnal Pengabdian

Vol 4, No 2, Desember 2020

ISSN $2580-7978$ (cetak) ISSN 2615 - 0794 (online)

\section{Penyuluhan Hipertensi}

Munculnya masalah kesehatan tidak hanya disebabkan oleh kelalaian individu, namun dapat pula disebabkan oleh ketidaktahuan masyarakat sebagai akibat dari kurangnya informasi yang benar mengenai suatu penyakit (Rahmadiana, 2012). Rendahnya pengetahuan tenaga kesehatan, pasien, dan masyarakat tentang hipertensi merupakan penyebab utama tidak terkontrolnya tekanan darah, terutama pada pasien hipertensi di Asia (Park, J.B., Kario, K., dan Wang, J.G., 2015).

Kegiatan pengabdian kepada masyarakat berupa penyuluhan tentang pemahaman pengukuran tekanan darah secara mandiri serta mengaplikasi kegiatan senam hipertensi. Keberhasilan target jumlah peserta dengan target jumlah peserta terpenuhi $90 \%$ kader kesehatan dilakukan penyuluhan dan menerima materi yang dilakukan oleh tim PKM. Ketercapaian tujuan pelatihan dapat dikatakan baik (80\%). dan setelah dilakukan tanya jawab dapat dilihat bahwa ada peningkatan pengetahuan dari kader kesehatan mengenai hipertensi dan komplikasi hipertensi dan bertujuan untuk meningkatkan pengetahuan dan pemahaman kader kesehatan mengenai hipertensi dan komplikasi hipertensi. Hasil evaluasi PKM bahwa kader kesehatan dapat memahami materi penyuluhan dari analisis data kuesioner dengan nilai rerata pre-test 69,55 dan nilai rerata posttest 82,22 .

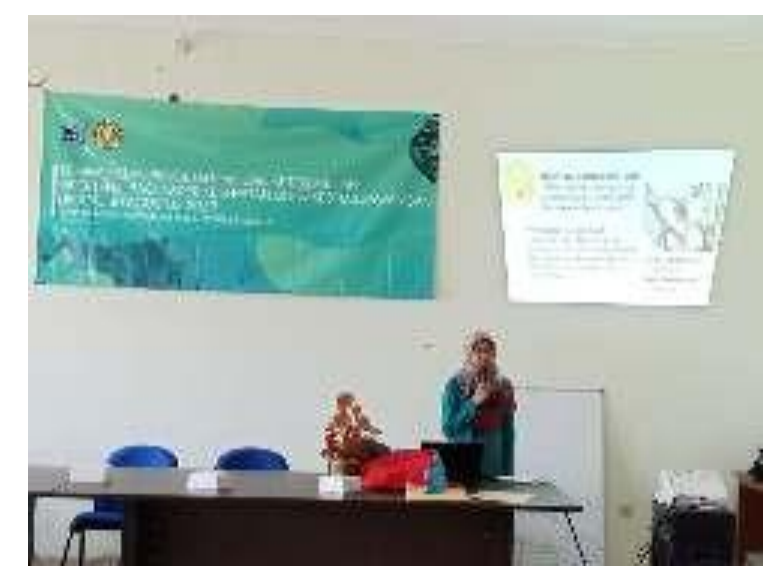

Gambat 1. Penyuluhan Hipertensi 
INTEGRITAS : Jurnal Pengabdian

Vol 4, No 2, Desember 2020

ISSN $2580-7978$ (cetak) ISSN 2615 - 0794 (online)

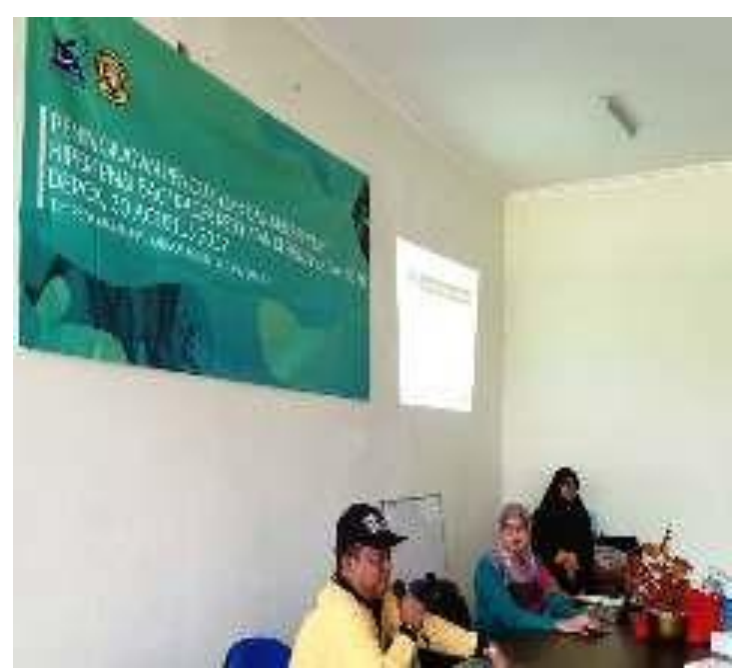

Gambat 2. Penyuluhan Hipertensi dan Stroke

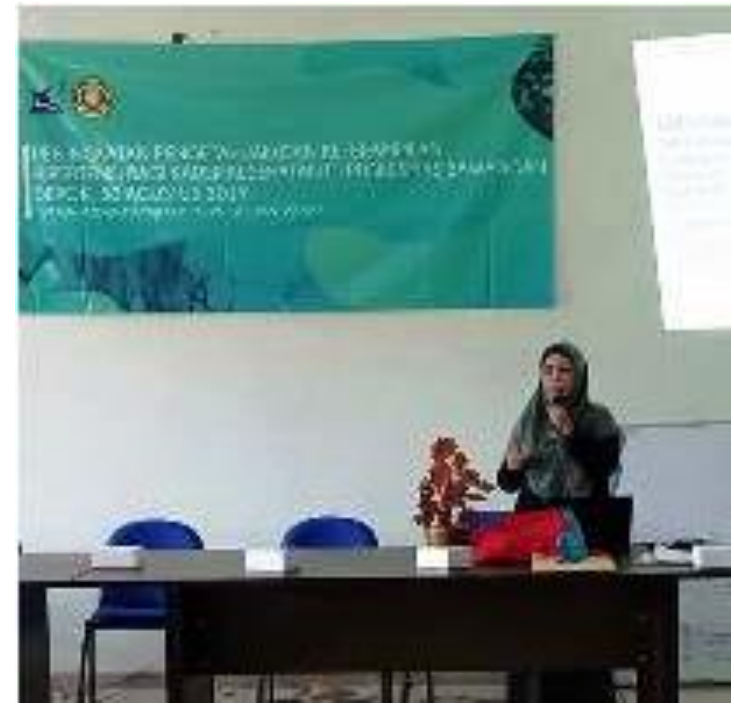

Gambat 3. Penyuluhan Hipertensi dan PJK

Pengukuran tekanan darah mandiri sudah dilakukan antara teman kader kesehatan dengan baik dan tepat serta mengaplikasi kegiatan senam hipertensi. 


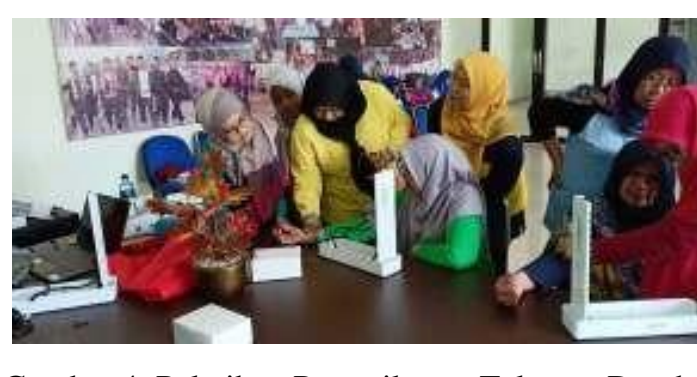

Gambat 4. Pelatihan Pemeriksaan Tekanan Darah

Salah satu cara untuk menurunkan tekanan darah adalah dengan melakukan senam secara teratur. Senam dapat meningkatkan aliran darah dan meningkatkan kebugaran (Anggriyana \& Proverawati, 2015). Selama ini kader di wilayah kerja Puskesmas Sawangan Depok belum mengetahui bagaiamana cara melakukan senam hipertensi, sehingga tim pengabdi memberikan pelatihan cara melaksanakan senam anti hipertensi Para kader terlihat antusias dalam melakukan senam hipertensi dan dapat mempraktekkan kembali kegiatan senam yang sudah diajarkan.

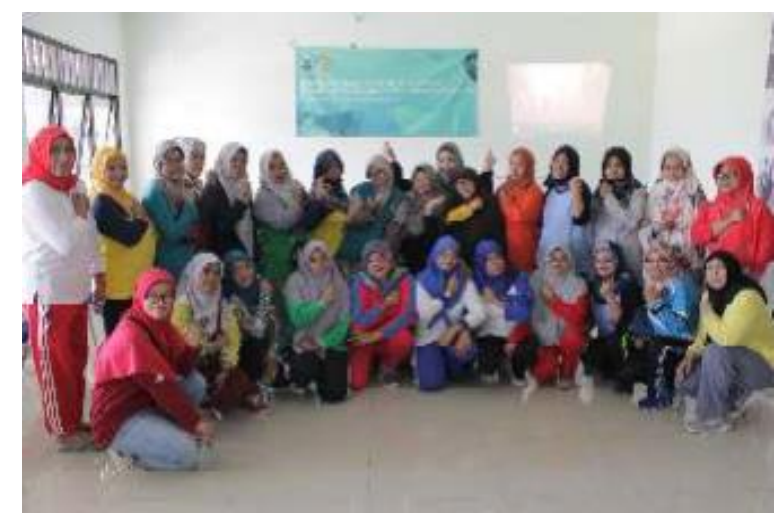

Gambar 5. Pelatihan Senam Hipertensi

\section{KESIMPULAN}

Penyuluhan dapat meningkatkan pengetahuan pengetahuan kesehatan tekanan darah tinggi, pengukuran tekanan darah, serta komplikasi pada tekanan darah tinggi (stroke dan Penyakit Jantung Koroner (PJK)) dan pengukuran tekanan darah secara mandiri dan berkala pada kader kesehatan di Puskesmas Sawangan Depok. 
INTEGRITAS : Jurnal Pengabdian

Vol 4, No 2, Desember 2020

ISSN $2580-7978$ (cetak) ISSN 2615 - 0794 (online)

\section{UCAPAN TERIMA KASIH}

Kami ucapkan terima kasih kepada Kepala Puskesmas, Bapak Camat, dan para kader kesehatan di wilayah Kecamatan Sawangan Depok dalam pelaksanaan kegiatan pengabdian kepada masyarakat.

\section{DAFTAR PUSTAKA}

Anggriyana, T, W., \& Proverawati, W. (2015). Senam kesehatan. Yogyakarta: Muha Medika.

Arieska Ann Soenarta, dkk. (2015). Pedoman Tatalaksana Hipertensi pada Penyakit Kardiovaskular. Edisi Pertama. Perhimpunan Dokter Kardiovaskular Indonesia (PERKI). Jakarta: Indonesian Heart Association

BPOM (2006). Kepatuhan Pasien: Faktor Penting Dalam Keberhasilan Terapi, info POM, Vol 7, No.5.

Dinas Kesehatan Kota Depok. (2017). Profil Kesehatan Kota Depok. http://www.depkes.go.id/resources/download/profil/PROFILKABKOTA 2017/3276JabarKotaDepok2017.pdf. Diakses pada tanggal 01 September 2019

Kemenkes. (2019). Hipertensi Penyakit Paling Banyak Diidap Masyarakat. http://www.depkes.go.id/article/print/19051700002/hipertensipenyakitpal ing-banyak-diidap-masyarakat.html. Diakses pada tanggal 01 September 2019

Kementrian Kesehatan. (2014). Peraturan Menteri Kesehatan Republik Indonesia Nomor 75 Tahun 2014. Retrieved from http://www.depkes.go.id/resources/download/peraturan/PMK-No-75-Th2014-ttg-Puskesmas.pdf.

Kemenkes. (2018). Riskesdas 2018. Retrieved from http://www.depkes.go.id/resources/download/infoterkini/materi_rakorpop 2018/Hasil\%20Riskesdas\%202018.pdf. Diakses pada tanggal 01 September 2019.

Park, J.B., Kario, K., dan Wang, J.G. (2015). Systolic Hypertension: an Increasing Clinical Challenge in Asia. Hypertension Research. 38 (4), 227-236. Retrieved from https://doi.org/10.1038/hr.2014.169.

Rahmadiana, M. (2012). Komunikasi Kesehatan: Sebuah Tinjauan. Psikogenesis. 1 (1). 88-94.

Rizka Aulia. (2018). PENGARUH PENGETAHUAN TERHADAP KEPATUHAN PASIEN HIPERTENSI DI INSTALASI RAWAT JALAN RSUD Dr. MOEWARDI SURAKARTA PERIODE FEBRUARI - APRIL 2018. Publikasi Ilmiah. Fakultas Farmasi Universitas 
INTEGRITAS : Jurnal Pengabdian

Vol 4, No 2, Desember 2020

ISSN $2580-7978$ (cetak) ISSN 2615 - 0794 (online)

Muhammad

Surakarta.

http://eprints.ums.ac.id/64675/3/NASKAH\%20PUBLIKASI\%20AULIA

\%20OK.pdf. Diakses pada 23 Agustus 2019.

Wahyuni Endah, dkk. (2019). Peningkatan Pengetahuan Hipertensi Dan Pelatihan

Penghitungan Nadi Dan Pengukuran Tekanan Darah Pada Kader

Posyandu Di Desa Sidorejo. Warta LPM. 22 (1), 47-51.

Yuli Ernawati. (2016). Analisis Efektifitas Biaya Penggunaan Antihipertensi Kombinasi Dua Obat Pada Pasien Hipertensi Rawat Jalan Di Rumah Sakit " X " Tahun 2012. Publikasi Ilmiah. Fakultas Farmasi Universitas Muhammad Surakarta. Retrieved from https://www.academia.edu/33225543/ANALISIS_EFEKTIFITAS_BIAY A PENGGUNAAN ANTIHIPERTENSI KOMBINASI DUA OBAT PADA PASIEN HIPERTENSI RAWAT_JALAN DI_RUMAH SAKIT $\underline{X}$ TAHUN 2012 Disusun sebagai_salah_satu syarat_menyelesaikan Program Studi Strata I pada Fakultas Farmasi. Diakses pada 23 Agustus 2019. 